\title{
Gold nanoparticles and their alternatives for radiation therapy enhancement
}

\section{Daniel R. Cooper, Devesh Bekah and Jay L. Nadeau*}

Department of Biomedical Engineering, McGill University, Montreal, QC, Canada

\section{Edited by:}

Jesús M. De La Fuente, Universidad de Zaragoza, Spain

Reviewed by:

Pedro Viana Baptista, Universidade

Nova de Lisba, Portugal

Wolfgang Parak, Universität

Marburg, Germany

*Correspondence:

Jay L. Nadeau, Department of

Biomedical Engineering, McGill

University, 316 Lyman Duff Building,

3775 University Street, Montreal,

QC H3A 2B4, Canada

e-mail: jay.nadeau@mcgill.ca
Radiation therapy is one of the most commonly used treatments for cancer. The dose of delivered ionizing radiation can be amplified by the presence of high-Z materials via an enhancement of the photoelectric effect; the most widely studied material is gold (atomic number 79). However, a large amount is needed to obtain a significant dose enhancement, presenting a challenge for delivery. In order to make this technique of broader applicability, the gold must be targeted, or alternative formulations developed that do not rely solely on the photoelectric effect. One possible approach is to excite scintillating nanoparticles with ionizing radiation, and then exploit energy transfer between these particles and attached dyes in a manner analogous to photodynamic therapy (PDT). Doped rare-earth halides and semiconductor quantum dots have been investigated for this purpose. However, although the spectrum of emitted light after radiation excitation is usually similar to that seen with light excitation, the yield is not. Measurement of scintillation yields is challenging, and in many cases has been done only for bulk materials, with little understanding of how the principles translate to the nanoscale. Another alternative is to use local heating using gold or iron, followed by application of ionizing radiation. Hyperthermia pre-sensitizes the tumors, leading to an improved response. Another approach is to use chemotherapeutic drugs that can radiosensitize tumors. Drugs may be attached to high-Z nanoparticles or encapsulated. This article discusses each of these techniques, giving an overview of the current state of nanoparticle-assisted radiation therapy and future directions.

Keywords: nanoparticle, scintillator, radiation therapy, photodynamic therapy, photosensitizer, radiosensitizer

\section{INTRODUCTION AND BACKGROUND}

Radiation therapy (XRT) is a critical component of the modern approach to curative and adjuvant treatment of cancers. XRT controls the growth of cancerous cells by bombardment with ionizing radiation, causing DNA damage by direct ionization or through generation of free radicals by ionization of water or oxygen molecules. Sufficient damage to DNA in this fashion can arrest cell growth and prevent metastasis. The primary drawback is collateral damage: there is little distinction in absorption between healthy and malignant tissues, and thus doses must be limited in order to mitigate unwanted damage to the tumor surroundings. External beam radiotherapy (EBRT) utilizes X-ray beams produced by orthovoltage units, or linear accelerators that may be spatially oriented, with beams shaped using multileaf collimators in order to maximize the specificity for the target. Distinct energy ranges are available for different EBRT targets: $40-100 \mathrm{kV}$ (kilovoltage or "superficial" X-rays) for skin cancers or other exposed structures; as well as $100-300 \mathrm{kV}$ (orthovoltage) and $4-25 \mathrm{MV}$ (megavoltage or "deep" X-rays) for sub-surface tumors. Techniques such as 3-dimensional conformal and intensity-modulated radiation therapies have vastly improved the targeting capabilities of external beam therapy, but naturally there is still a strong desire to be able to further reduce the doses required for effective treatment. The SI derived unit for absorbed dose is the gray (Gy), equivalent to one joule of energy deposited by ionizing radiation per kilogram of matter $(1 \mathrm{~Gy}=1 \mathrm{~J} / \mathrm{kg}=$ $1 \mathrm{~m}^{2} / \mathrm{s}^{2}$ ).

Brachytherapy, or internal radiotherapy, utilizes a radioactive source to provide a steady or pulsed dose of radiation to a small tissue volume. It is typically used for cervical, prostate, breast and skin cancers. Radioactive sources include ${ }^{125} \mathrm{I}$ and ${ }^{103} \mathrm{Pd}$, which produce $\gamma$ rays of $\sim 20-35 \mathrm{keV},{ }^{192} \operatorname{Ir}(\gamma$ rays, $300-610 \mathrm{keV}),{ }^{137} \mathrm{Cs}$ $(\gamma$ rays, $662 \mathrm{keV}),{ }^{60} \mathrm{Co}(\gamma$ rays, 1.17 and $1.33 \mathrm{MeV}),{ }^{198} \mathrm{Au}(\gamma$ rays, $410-1009 \mathrm{keV}),{ }^{226} \mathrm{Ra}(\gamma$ rays, $190-2430 \mathrm{keV})$, and ${ }^{106} \mathrm{Ru}$ which decays primarily through $\beta^{-}$emission at $3.54 \mathrm{MeV}$. Seeds of the listed materials can provide doses of up to $12 \mathrm{~Gy} /$ hour (high dose rate or HDR brachytherapy), though typical low dose rate (LDR) treatments amount to around 65 Gy over 5-6 days.

Heavy elements can be potent radiosensitizers (Kobayashi et al., 2010). It has been demonstrated that platinum-containing DNA-crosslinking drugs such as Cisplatin can enhance the effects of ionizing radiation through the "high $\mathrm{Z}$ effect," or what has come to be known as Auger therapy. Heavy elements have significantly higher photoelectric cross-sections than soft tissue for sub-MeV energies, approximated for "X-ray energies" by the equation:

$$
\sigma_{p e} \propto \frac{Z^{n}}{E^{3}}
$$

where $\sigma_{p e}$ is the cross-section, $E=h v$ is the photon energy, $Z$ is the atomic number, and $n$ varies between 4 and 5 depending 
on the value of $E$. The photoelectric effect dominates below the electron rest energy of $511 \mathrm{keV}$, beyond which inelastic Compton scattering becomes more prevalent. As the photon energy decreases, it is no longer able to eject inner-shell electrons, producing the characteristic sawtooth pattern with $\mathrm{K}, \mathrm{L}$, and $\mathrm{M}$ edge structures. When ionized by $\mathrm{X}$-ray or $\gamma$ ray energy, mid- to high- $\mathrm{Z}$ elements (roughly $\mathrm{Br}$ and up) can produce a cascade of low-energy Auger electrons that can locally enhance the effective radiation dose (Kobayashi et al., 2010). Dense inorganic nanoparticles can also provide radiation dose enhancement that depends upon the composition and size of the particles, uptake of particles into cells, and the energy of the applied radiation.

\section{GNRT}

$\mathrm{Au}$ nanoparticles have been under investigation for several years as possible agents for selective amplification of radiation dose in tumors, a concept called "gold nanoparticle-assisted radiation therapy” or GNRT (McMahon et al., 2008; Brun et al., 2009; Cho et al., 2009; Rahman et al., 2009; Van den Heuvel et al., 2010; Leung et al., 2011; Zhang et al., 2012). Reviews of this work can be found in Jelveh and Chithrani (2011), Butterworth et al. (2012), Jain et al. (2012), Babaei and Ganjalikhani (2014), Su et al. (2014).

The earliest studies used bulk or micro-sized gold to enhance radiation dose. Although this could be effective in vitro at a range of energies, micron-sized particles are not taken up well in vivo, even after intratumoral injection (Herold et al., 2000). Later experiments focused on Au nanoparticles or nanoclusters (1.9 nm diameter). When injected intravenously, these ultrasmall particles rapidly accumulated in cancer tissue, with $2.7 \mathrm{~g} \mathrm{Au} / \mathrm{kg}$ body weight resulting in $7 \mathrm{mg} \mathrm{Au} / \mathrm{g}$ in tumor almost immediately after injection. Irradiation was performed about $60 \mathrm{~s}$ after injection, and with typical $250 \mathrm{kVp}$ X-ray therapy, 1-year survival was $86 \%$ (compared to $20 \%$ with X-rays alone and $0 \%$ with gold alone) (Hainfeld et al., 2004). This result was followed by theoretical and experimental papers examining the mechanism of $\mathrm{Au}$ nanoparticle action as well as attempting to optimize Au particle concentration, size, and the energy and dose of applied X-rays (Cho et al., 2009; Zhang et al., 2009; Van den Heuvel et al., 2010; Leung et al., 2011).

\section{IMPROVING GNRT BY TARGETING}

A significant problem with ultrasmall, nontargeted nanoparticles is rapid excretion by the kidneys. The amount of Au needed in early studies ( $>2 \mathrm{~g} \mathrm{Au} / \mathrm{kg}$ body weight) represents a very large amount of $\mathrm{Au}$ for human use. This is impractical, costly, and may cause toxicity. Achieving therapeutic levels in tumor with less delivered total $\mathrm{Au}$ is needed. In addition, irradiation in the mouse studies was performed immediately after particle injection. This is not practical in the clinic and may not work well in humans. Particles with longer circulation times, which can be delivered in multiple doses, are desirable for clinical applications. Optimizing the size, surface chemistry, and targeting of the Au nanoparticles may improve circulation times and accumulation in specific tumors.

The increased metabolic rate of tumors relative to normal tissue results in a high demand for glucose. Several studies have used

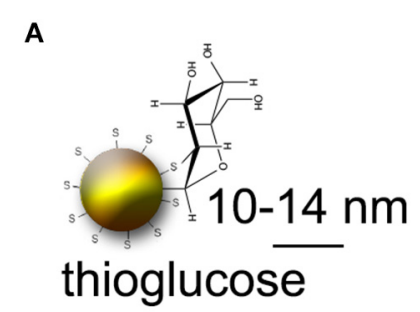

B

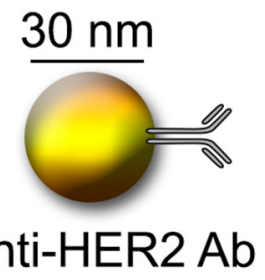

C

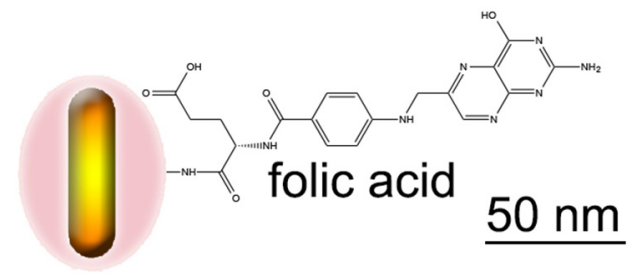

D

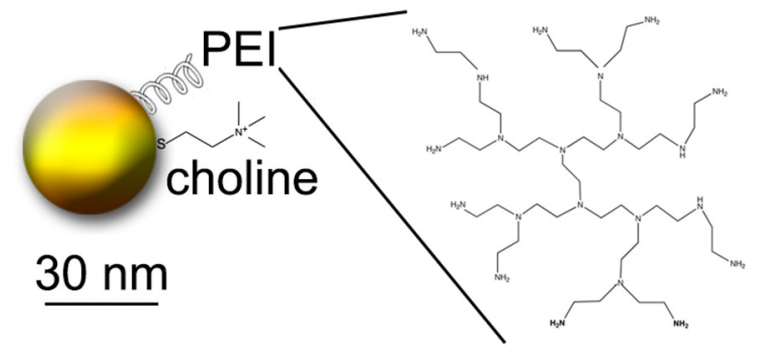

FIGURE 1 | Approaches to creating tumor-targeted Au nanoparticles. Molecules not to scale. (A) Thioglucose-conjugated Au nanoparticles. (B) Au nanoparticles conjugated to Herceptin (anti-HER2 antibody). (C) Au nanorods conjugated to folic acid. (D) PEl-coated Au nanoparticles conjugated to choline.

thioglucose-conjugated $\mathrm{Au}$ nanoparticles (Figure 1A) in order to increase uptake by cancer cells. One study using $\sim 14 \mathrm{~nm}$ $\mathrm{Au}$ demonstrated significantly increased uptake of thioglucoseconjugated particles by an ovarian cancer cell line after 8-96 h of incubation (Geng et al., 2011). A significant increase in inhibition was seen in the presence of $5 \mathrm{nM}$ particles using $90 \mathrm{kVp}$ or $6 \mathrm{MV} \mathrm{X}$-rays; dose enhancement was significant relative to control beginning at $5 \mathrm{~Gy}$ and extending to $20 \mathrm{~Gy}$, where all cells were inhibited even in the absence of particles. Another study compared cysteamine and thioglucose-coated $15 \mathrm{nM}$ Au nanoparticles in breast cancer and normal breast cell lines (Kong et al., 2008b). Cysteamine-coated particles were taken up 3- to 4-fold more efficiently than glucose-coated particles. However, when applied to cells at concentrations that led to similar intracellular Au concentrations, glucose-coated particles led to increased radiosensitization relative to cysteamine-capped particles. Interestingly, radiosensitization by Au was not seen in a nonmalignant breast cell line, although the cells grew at the same rate as the cancer cells and took up an equal number of particles. The ability of ${ }^{167} \mathrm{Cs}$ and ${ }^{60} \mathrm{Co}$ sources to inhibit the cancer cells was also demonstrated in this paper.

The use of larger Au particles ( $57 \mathrm{~nm}$ and $84 \mathrm{~nm}$ ) coated with thioglucose has been studied in another report (Song et al., 2013). These particles were taken up in equal numbers by HeLa cells. 
Surprisingly, unconjugated particles showed a greater radiosensitizing effect than thioglucose-conjugated particles, which the authors attributed to possible absorbance of singlet oxygen by the thioglucose shell.

Another study used the humanized anti-HER2 antibody Trastuzumab (Herceptin), PEGylated and conjugated to $30 \mathrm{~nm}$ $\mathrm{Au}$ particles, for delivery to MDA-MB-361 breast cancer (Chattopadhyay et al., 2013) (Figure 1B). Both in vitro and in vivo studies were performed. In vitro, an effective dose enhancement factor of 1.6 was seen in the presence of $2.4 \mathrm{mg} / \mathrm{mL}$ particles using $100 \mathrm{kVp}$ X-rays. Delivery to MDA-MB-361 xenografts was done intratumorally, with $\sim 0.8 \mathrm{mg}$ total $\mathrm{Au}$ used $(4.8 \mathrm{mg} / \mathrm{g}$ tumor). $11 \mathrm{~Gy}$ of $100 \mathrm{kVp}$ image guided X-ray irradiation was performed $24 \mathrm{~h}$ after injection. This subtoxic dose led to a $46 \%$ reduction in tumor size relative to irradiation alone, with no damage to normal tissue or systemic toxicity.

Folic acid is another nutrient for which the need is increased in cancer cells. Conjugation to folate has been used for a wide variety of targeting applications for cancer and inflammatory diseases; a review may be found here (Low et al., 2008). Intra-operative tumor imaging using folate targeting has recently moved to the clinic for ovarian cancer (van Dam et al., 2011). In terms of GNRT, one study reported the use of silica-modified Au nanorods ( $~ 50 \mathrm{~nm}$ long) conjugated to folate (Huang et al., 2011) (Figure 1C). The rods were taken up by MGC803 human gastric carcinoma cells. 6 Gy of $\mathrm{X}$-irradiation led to a $60 \%$ decrease in cell viability in the presence of $12.5 \mu \mathrm{M}$ rods relative to cells without Au. The study also demonstrated uptake of the rods by MGC803 xenografts in nude mice, with contrast sufficient for X-ray imaging. No radiation experiments on animals were reported.

Cancers are also often distinguished by a lower $\mathrm{pH}$ than healthy cells due to hypoxia and resulting anaerobic metabolism within tumors. The $\mathrm{pH}$-sensitive pHLIP peptide was used in one study to target $\mathrm{Au}$ nanoparticles to mice bearing $\mathrm{HeLa}$ tumors (Yao et al., 2013). Although radiation was not performed, accumulation of Au in tumors sufficient for radiotherapy enhancement was demonstrated, with the stated goal of using the construct for this purpose.

Prostate cancer is an excellent target for nanoparticleenhanced radiation, since it is often treated by brachytherapy and is accessible to intratumoral injection. Choline is a ubiquitous molecule in all cells for which overactivity of processing enzymes (choline kinase) has been found in prostate tumors. One study reported development of polyethylene imine (PEI)- and cholineconjugated Au nanoparticles for the purpose of targeting prostate cancer for GNRT (Razzak et al., 2013) (Figure 1D). While no radiation experiments were performed in this study, favorable pharmacokinetics were shown in mice.

These studies illustrate that targeted GNRT remains an area requiring substantial further investigation. While one or more targeting agents may be conjugated to $\mathrm{Au}$ nanoparticles, and while these may improve delivery in vitro and even in vivo, it is not fully established whether these formulations improve tumor response to radiation therapy. The possibility that an organic shell can absorb reactive oxygen species deserves further inquiry. The size of the nanoparticles used, the density of targeting ligands, and the delivery method (IV, intratumoral, concentration, timing) all need to be optimized. The good news is that many of these formulations use FDA-approved ingredients, some of which are currently in the clinic for imaging. Optimization in animal studies should thus lead to rapid clinical translation.

\section{IMPROVING GNRT BY ADDITION OF PHOTOTHERMAL THERAPY}

Hyperthermia therapy is a minimally invasive treatment in which the temperature is increased locally (up to $44^{\circ} \mathrm{C}$ ) to kill malignant cells. Even though hyperthermia can kill cells on its own, it is more often used in combination with other treatments such as radiotherapy or chemotherapy (Wust et al., 2002); such combinations are in clinical trials (Vernon et al., 1996; van der Zee et al., 2000; Zagar et al., 2010). An increase in nuclear damage is one of the mechanisms through which cells are radiosensitized after hyperthermia (Wust et al., 2002; Kampinga, 2006). In addition, the higher temperature causes dilation of the blood vessels, increasing oxygenation of the tumor (Griffin et al., 1996; Song et al., 2009). Since oxygen is a potent radiosensitizer, it can increase the damage to the tumor through generation of free radicals.

Methods to locally heat the tumor region include high intensity focused ultrasound (HIFU), microwave heating, magnetic hyperthermia, and photothermal therapy. In photothermal therapy, a light source (usually infrared) is used to deliver heat to the tumor. Such approaches are difficult to target, but delivery of nanomedicines to the tumor could improve the local heating profile. Most studies have looked at gold nanoparticles and nanorods for this purpose, because exposure of Au nanoparticles to IR light causes a local temperature increase due to surface plasmon resonance (El-Sayed et al., 2006; Huang et al., 2006; Gobin et al., 2007; Hainfeld et al., 2010; Verma et al., 2014). By modifying the size and shape of these nanoparticles, the resonance peak can be tuned to different wavelengths in the IR.

Delivery of gold followed by heating and ionizing radiation has proved to be a promising approach in pre-clinical studies. Gold nanoshells with a $120 \mathrm{~nm}$ silica core and a $12-15 \mathrm{~nm}$ shell were used in one study (Diagaradjane et al., 2008) to treat a murine xenograft model of human colorectal cancer. Localized hyperthermic treatment followed 5 min later by a 10 Gy X-ray dose were given $20-24 \mathrm{~h}$ after IV delivery of the nanoshells. The tumor volume doubling time was significantly greater for the treated mice. Two mechanisms were identified as contributing to the treatment's efficacy: an increase in perfusion resulting in a decrease in tumor hypoxia, and vascular collapse in the tumor due to accumulation of nanoparticles around the blood vessels. Another study confirmed these results using similar gold nanoshells in two murine breast cancer models (Atkinson et al., 2010).

Another study used gold nanorods modified with silica and conjugated to folic acid (Huang et al., 2011) to test the effects of photothermal and radiation therapy on MGC803 gastric cancer cells. The two treatments were tested separately and not combined. For the radiation treatment, a $6 \mathrm{MeV}$ source was used to deliver doses of up to $10 \mathrm{~Gy}$. Cell survival with radiation decreased in a concentration-dependent fashion with nanoparticle addition; the particles were non-toxic in the absence of radiation. 
Photothermal therapy consisted of 3 min of irradiation with a $30 \mathrm{~mW}, 808 \mathrm{~nm}$ laser source. Apoptosis was seen after treatment in the presence of the gold particles.

A recent study (Hainfeld et al., 2010) calculated the radiation dose required to control $50 \%$ of tumors (TCD50) in a mouse squamous cell carcinoma model. Gold nanoparticles were delivered intratumorally, and $24 \mathrm{~h}$ later the tumor was heated to $48^{\circ} \mathrm{C}$ for $5 \mathrm{~min}$ at $1.5 \mathrm{~W} / \mathrm{cm}^{2}$ followed by X-ray irradiation at $100 \mathrm{kVp}$ (7.5 Gy/min). TCD50 was reduced from $55 \mathrm{~Gy}$ to less than $15 \mathrm{~Gy}$.

These studies illustrate one of the biggest problems of the approach, which is the need for simultaneous delivery of heating and radiation, which poses logistic problems in the clinic (Wust et al., 2002). Other drawbacks include a lack of specificity and the difficulty of heating deep tumors.

\section{ALTERNATIVES TO GOLD: BISMUTH AND IRON}

Alternatives to Au are being sought that are more effective and/or less costly. Bismuth ( $\mathrm{Bi}, Z=83)$ and platinum $(\mathrm{Pt}, Z=78)$ have been shown in at least one theoretical study to yield a dose enhancement factor higher than $\mathrm{Au}$, with $\mathrm{Bi}$ being the highest. Dose enhancement is predicted to increase with decreasing nanoparticle size, because the smaller nanoparticles accumulate closer to the nucleus, where they can cause the greatest damage. The dose enhancement is also expected to be greater when the average energy is close to the K-edge of the element (Ngwa et al., 2010; Hossain and Su, 2012). A radiochromic dosimeter was used in another study to experimentally measure the dose enhancement of bismuth oxide $\left(\mathrm{Bi}_{2} \mathrm{O}_{3}\right)$ nanoparticles. Using a $100 \mathrm{kV}$ $\mathrm{X}$-ray source and an irradiation dose of $10 \mathrm{~Gy}$, the radiation dose in a water-equivalent matrix doped with $0.5 \mathrm{mM}$ of $50 \mathrm{~nm} \mathrm{Bi}_{2} \mathrm{O}_{3}$ nanoparticles was $>80 \%$ higher than in the control compartment (Alqathami et al., 2013). Another study (Zhang et al., 2014) looked at the dark toxicity, biodistribution, and radiation effects of bismuth selenide $\left(\mathrm{Bi}_{2} \mathrm{Se}_{3}\right)$ nanoplatelets in cell lines and mice. The platelets were not significantly toxic to either cells or mice, with over $93 \%$ of the Bi cleared from the body 90 days after treatment. Significant radiation dose enhancement was observed after irradiation doses of up to $8 \mathrm{~Gy}$.

Gadolinium ( $\mathrm{Gd}, Z=64$ ) represents another alternative to gold nanoparticles. In addition to having a relatively high atomic number, Gd is already routinely used as a contrast agent in MRI. $\mathrm{Gd}_{2} \mathrm{O}_{3}$ core nanoparticles encapsulated in a polysiloxane shell have shown potential as an image guided radiotherapeutic tool in a gliosarcoma rat model (Le Duc et al., 2011). Accumulation of the nanoparticles in the tumor after saphenous vein injection was demonstrated using MRI, and the tumor-bearing rats were treated with microbeam radiation therapy, with a significant increase in survival in the nanoparticle-treated group. Another study using a rat brain tumor model confirmed that ultra-small Gd-based nanoparticles accumulate in brain tumors after IV injection (Miladi et al., 2013).

Magnetic particles such as iron oxide may also be used for combined hyperthermia and radiation. By using an alternating magnetic field to excite magnetic nanoparticles, local temperature increases can be achieved. The advantages of iron oxide include low toxicity, ease of synthesis, and the ability to perform image guidance using MRI. Dextran-coated iron oxide has been shown to reduce tumor growth in a syngeneic mouse breast cancer model when hyperthermia and radiation were combined (Giustini et al., 2011).

Several studies have looked at radiosensitization properties of iron oxide nanoparticles. Using $6 \mathrm{MeV}$ X-rays on a human prostate carcinoma cell line (DU145), $1 \mathrm{mg} / \mathrm{ml}$ of $\mathrm{Fe}_{3} \mathrm{O}_{4}$ nanoparticles resulted in a dose enhancement factor of approximately 1.2 (Khoei et al., 2014). Another study suggested that superparamagnetic iron oxide nanoparticles (SPIONs) can radiosensitize tumor cells by catalyzing ROS formation. Uncoated, citrate-coated, or malate-coated SPIONs were added to MCF-7, 3T3, and Caco-2 cells. Uncoated SPIONS caused dark toxicity, with no increase in ROS upon 1 or 3 Gy irradiation. In contrast, coated SPIONS were non-toxic in the absence of radiation, but resulted an increase of up to $300 \%$ in the fluorescence intensity of the ROS reporter dichlorofluorescein diacetate (DCF-DA) (Klein et al., 2014).

\section{SCINTILLATING NANOPARTICLES FOR RADIATION/PHOTODYNAMIC "HYBRID” THERAPY INTRODUCTION AND CONCEPT}

A 2006 study proposed a new approach to nanoparticle-based therapies aiming to combine and enhance the effects of radiation therapy and photodynamic therapy (PDT) through the use of scintillating nanoparticles conjugated to photosensitizer molecules (Chen and Zhang, 2006). The concept is simple: attach a dye used for PDT to a nanoparticle that emits light when excited by therapeutic radiation (scintillates). If the scintillation emission overlaps the absorbance spectrum of the dye, the dye will generate singlet oxygen as it does with light-excited PDT (Figure 2). Many conventional photosensitizers are based on naturally occurring porphyrin, chlorin, and bacteriochlorin structures comprised of highly conjugated heterocyclic macrocycles (Figure 3A). These molecules have a strong absorbance peak in the UV to blue range (Soret band) as well as numerous weaker peaks in the visible (Figure 3B).

This idea has attracted significant attention over the past few years (Cheng and Lo, 2011) because it promises to combine the tissue penetration depth of radiation with the efficacy and benign side effect profile of PDT. PDT results in less damage to normal tissue than does radiation therapy; does not induce scarring; may be repeated multiple times; and may spark immune responses that help destroy the tumor. However, because of the limited tissue penetration depth of visible and even near-IR light, this therapy is restricted to only the most superficial cancers, such as non-melanoma skin cancer and bladder cancer.

The challenge is to develop stable, nontoxic nanoscintillators that may be delivered to cells. Several varieties of doped insulator and semiconductor nanoparticles have been proposed to fill this role. While scintillation has been demonstrated for $\mathrm{CdSe} / \mathrm{ZnS}$ quantum dots (Létant and Wang, 2006), they have poor radiation hardness and degrade rapidly under $\gamma$ ray exposure (Withers et al., 2008). As the toxicity of these materials is also primarily related to their chemical degradation, alternatives are necessary. The development of such alternatives is mostly in early stages. Although many of the approaches to surface chemistry and targeting that have been used for gold could be applied to these other 


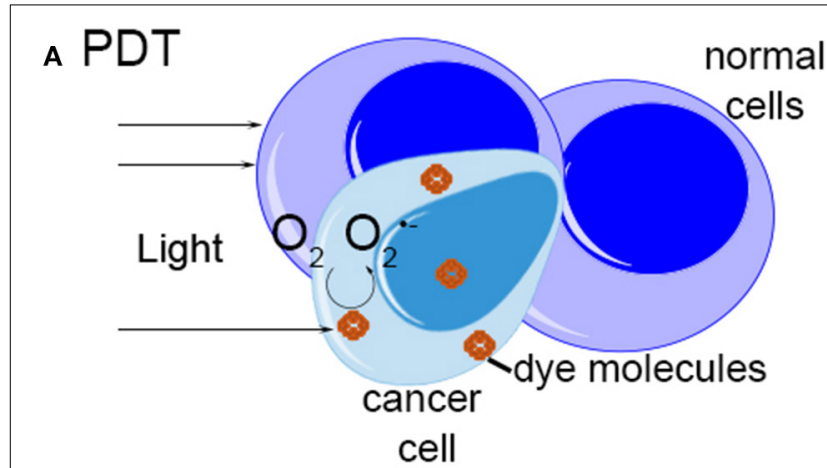

в PDT/radiotherapy hybrid

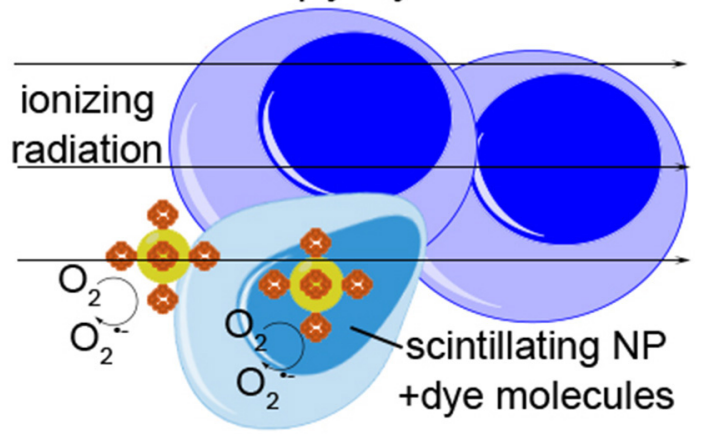

FIGURE 2 | Schematic of photodynamic therapy and radiotherapy-photodynamic therapy "hybrid" approach. (A) In photodynamic therapy, photosensitizer dye molecules collect preferentially in malignant or inflamed tissue. Light is used to excite the dye, generating reactive oxygen species which lead to cell killing. (B) In the "hybrid" approach, ionizing radiation is used to excite scintillating nanoparticles, which may be located deep within tissue. The nanoparticles transfer energy to attached photosensitizer molecules, generating ROS and killing cells by the same mechanism as photodynamic therapy.

materials, this has not yet been attempted. Some of the materials also show specific chemical challenges as we will discuss in Section Biocompatibility of lanthanide-based materials.

\section{SCINTILLATION}

Scintillation, or radioluminescence (RL), is the process whereby a material, referred to as a scintillator, produces light upon interaction with ionizing radiation. Inorganic nanoparticles (NPs) doped with lanthanides present an attractive, radiostable alternative to quantum dots for scintillation.

\section{Introduction to lanthanide luminescence}

Lanthanides are well known for the luminescence of their trivalent cations, which emit primarily through phosphorescence resulting from electronic transitions within the $4 f$ shell (Bünzli and Eliseeva, 2010). Because these transitions are "forbidden" by Laporte's parity selection rule (formally prohibiting electric dipole transitions between states that conserve parity), they have low absorption cross-sections and their photoluminescence is commonly sensitized by $\mathrm{Ce}^{3+}$ (for downconversion, with $\mathrm{Tb}^{3+}$ acceptor) or $\mathrm{Yb}^{3+}$ (for upconversion, with $\mathrm{Tm}^{3+}, \mathrm{Er}^{3+}$, and $\mathrm{Ho}^{3+}$ acceptors), though more complex combinations of lanthanides are certainly possible. The efficiency of both processes benefits

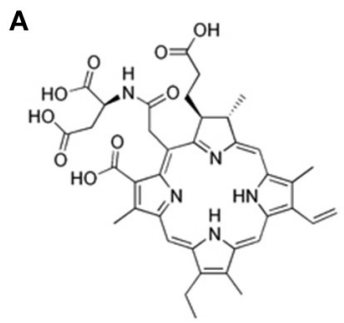

Mono-L-aspartyl chlorin e6 (NPe6)

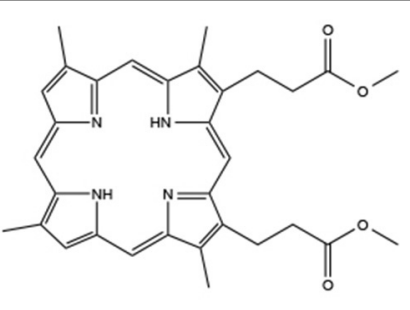

Deuteroporphyrin IX

$\mathbf{B}$

B

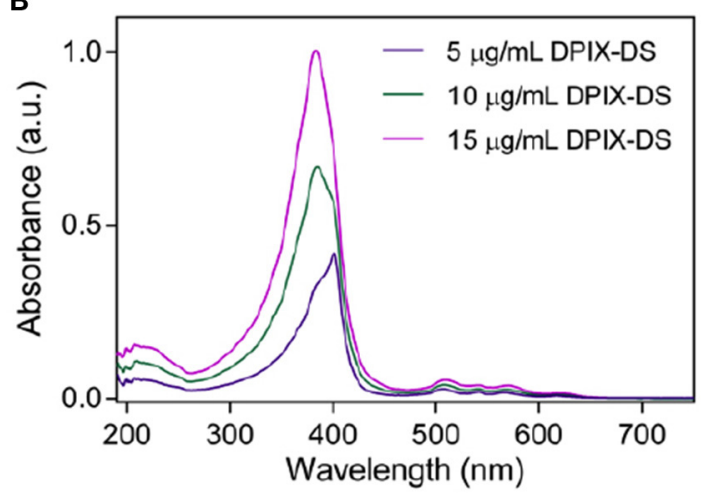

FIGURE 3 | Photosensitizers. (A) Typical photosensitizer structures: mono-L-aspartyl chlorin e6 (Talaporfin sodium), a PDT drug that can be isolated from algae or green plants (approved in Japan and in Phase III trials in the U.S.); deuteroporphyrin IX, a candidate photosensitizer with several possible derivatives. (B) Absorbance spectra of different concentrations of deuterophorphyrin IX disulfonic acid (DPIX-DS). Note the strength of the Soret band (UV-blue) compared to the peaks in the redder regions.

from a low phonon energy host, though is of increasing importance for lower energy transitions. In the case of upconverting NPs, hexagonal phase ( $\beta$ phase) $\mathrm{NaYF}_{4}$ or isostructural $\mathrm{NaGdF}_{4}$ are generally the preferred host materials.

The mechanism of cerium luminescence is distinct from most other lanthanides. Neutral cerium has a $[\mathrm{Xe}] 4 \mathrm{f}^{1} 5 \mathrm{~d}^{1} 6 \mathrm{~s}^{2}$ electronic configuration; in solution or in solid hosts, the +3 or +4 oxidation states are the most common. Only the +3 state is luminescent, though the +4 state also has important implications for redox activity. In the +3 state, the $6 s$ and $5 d$ electrons are lost, leaving one optically active electron in the shielded $4 f$ shell. Fluorescence $(\Delta S=0)$ arises from parity-allowed, high oscillator strength $4 f-5 d$ transitions. Because the $5 d$ orbitals are external, these transitions are sensitive to the crystal field, and vary in energy across a substantial range depending on the host material (Dorenbos, 2000).

Cerium-doped lanthanum fluoride $\left(\mathrm{Ce}_{x} \mathrm{La}_{1-x} \mathrm{~F}_{3}\right)$ shows luminescence in the UV-blue (corresponding well to the Soret band) and so is a likely candidate for useful energy transfer to photosensitizers.

\section{Mechanisms of scintillation}

RL mechanisms of bulk $\mathrm{Ce}_{x} \mathrm{La}_{1-x} \mathrm{~F}_{3}$ crystals were elucidated in the late $80 \mathrm{~s}$ and early-to-mid $90 \mathrm{~s}$ as candidates for radiation 
detection purposes (Moses and Derenzo, 1989, 1990; Wojtowicz et al., 1992, 1994; Lempicki et al., 1993; Moses et al., 1994; Rodnyi et al., 1995). Though the scintillation was found to be significantly faster than commonly used scintillators at the time (BGO, CsI:Tl, $\mathrm{NaI}: \mathrm{Tl})$ on a per-photon basis, the overall light output was found to be unexpectedly weak, with variable luminescence that was significantly dependent on the quality of the crystal and the presence of defects. This variability precluded their use as reliable detectors for the most part, at least compared to other options being developed concurrently, such as $\mathrm{PbWO}_{4}$.

The general process of activator-based scintillation occurs in three steps: first, conversion of absorbed ionizing radiation energy into electronic-lattice excitations (electron-hole pairs and/or excitons), followed by transfer of the excitation energy to the emitting centers and then luminescence. The overall scintillation efficiency is given by the product of the individual efficiencies:

$$
\eta=\beta S Q, \quad 0 \leq \eta, \beta, S, Q \leq 1
$$

where $\beta$, the efficiency of the conversion process, encompasses the fraction of absorbed energy lost to optical phonons, $S$ is the efficiency of the transfer process, and $Q$ is the luminescence quantum yield of the emitting center. The overall light output $L$ (in photons $/ \mathrm{MeV}$ ) is given by:

$$
L=n_{e-h} \eta=\frac{10^{6}}{2.3 E_{g}} \beta S Q
$$

where $n_{e-h}$ is the number of $e-h$ pairs or excitons that are generated per $\mathrm{MeV}$ of absorbed radiation, discounting losses to optical phonons, and $E_{g}$ is the band gap of the host (in $\mathrm{eV}$ ). The factor of 2.3 is related to the derived minimum incident photon energy required to generate a single $e-h$ pair (Robbins, 1980), $\xi_{\min }=2.3 E_{g}$, and so $n_{e-h}=E / 2.3 E_{g}$ where $E$ is the energy of the incident photon, in this case $1 \mathrm{MeV}=10^{6} \mathrm{eV}$.

Low phonon energy hosts such as $\mathrm{LaF}_{3}$ tend toward higher values of $\beta$, while the transfer process $S$ is relatively inefficient compared to pentaphosphate or orthophosphate hosts (Lempicki et al., 1993). The $\beta$ and $S$ mechanisms of $\mathrm{Ce}_{\mathrm{x}} \mathrm{La}_{1-\mathrm{x}} \mathrm{F}_{3}$ were determined to consist of three distinct processes that have different relative contributions depending on the value of $x$ : (i) direct excitation of $\mathrm{Ce}^{3+}$ by X-rays or secondary electrons, (ii) ionization of $\mathrm{Ce}^{3+}$ followed by electron capture and formation of bound excitons, or (iii) energy transfer to $\mathrm{Ce}^{3+}$ from lattice excitations of the bulk matrix. At lower concentrations of $\mathrm{Ce}^{3+}$, up to $x \sim 0.5$, mechanism (iii) dominates the scintillation response. At higher doping levels, mechanism (i) is predominant, accounting for a large fraction of the light output in $\mathrm{CeF}_{3}$. It has recently been demonstrated that co-doping single crystals of $\mathrm{YPO}_{4}: \mathrm{Ce}^{3+}$ with $\mathrm{Pr}^{3+}$, which act as electron traps, can improve scintillation efficiency by minimizing the influence of defects as well as mitigating the effects of damage caused by prolonged irradiation (Moretti et al., 2014).

\section{Nanoscintillators}

A number of reports have investigated the scintillation response of $\mathrm{Ce}_{x} \mathrm{La}_{1-x} \mathrm{~F}_{3}$ nanocomposites, where small NPs $(\sim 10 \mathrm{~nm}$ in diameter) are cast into oleic acid or polymer matrices with consistencies ranging from liquid to waxy. In initial studies, nanocomposites exhibited photopeaks for ${ }^{137} \mathrm{Cs},{ }^{241} \mathrm{Am}$, and ${ }^{57}$ Co irradiation (McKigney et al., 2007a,b). Most recently, a modest scintillation response (compared to a BC-400 polyvinyltoluene detector) has been shown for $25 \%$ NP-loaded composites exposed to several sources: ${ }^{22} \mathrm{Na}(3.22 \mu \mathrm{Ci}),{ }^{60} \mathrm{Co}(3.78 \mu \mathrm{Ci})$, ${ }^{137} \mathrm{Cs}(31.9 \mu \mathrm{Ci}),{ }^{241} \mathrm{Am}(9.09 \mu \mathrm{Ci})$, and ${ }^{252} \mathrm{Cf}(5.03 \mu \mathrm{Ci})$ (Guss et al., 2013). For radiation detection purposes, fast lifetimes are typically preferred, whereas for bioconjugates, short lifetimes may preclude efficient energy transfer if it is outcompeted by luminescence or quenching processes.

While the scintillation of cerium in simple fluoride or phosphate hosts is well studied, it is just one of a number of possible scintillation mechanisms. In the late $2000 \mathrm{~s}$, a number of reports were released discussing the possibilities and limitations for nanoscintillators in a broad sense, including the demonstration of a few crucial nanoscale phenomena (Klassen et al., 2008, 2009; Dujardin et al., 2010; Kortov, 2010). Several research groups are now engaged in the development of a wider variety of nanoscintillators, either through adaptation of known scintillating materials to the nanoscale, or through the creation of novel compositions. Many of these are based on luminescent "activator" dopants, including lanthanides $\left(\mathrm{Ce}^{3+}, \mathrm{Pr}^{3+}, \mathrm{Tb}^{3+}\right.$, or $\left.\mathrm{Eu}^{2 / 3+}\right)$. RL spectra have been published for a number of fluoride nanoscintillators, including powdered $\mathrm{LaF}_{3}: \mathrm{Eu}(\sim 4.4 \mathrm{~nm})$, $\mathrm{BaF}_{2}: \mathrm{Ce}(\sim 10 \mathrm{~nm})$, and $\mathrm{CaF}_{2}: \mathrm{Eu}(\sim 18 \mathrm{~nm})$ NPs under excitation by a $40 \mathrm{kV}$ Bullet $\mathrm{X}$-ray tube and $\mathrm{CaF}_{2}: \mathrm{Eu}^{3+}$ excited by a $1 \mu \mathrm{Ci}{ }^{241} \mathrm{Am}$ source $\left(E_{\alpha}=5.5 \mathrm{MeV}, E_{\gamma}=60 \mathrm{keV}\right.$ ) (Jacobsohn et al., 2011). The authors suggest that in such doped ionic crystals, where the diffusion length of $e-h$ pairs may be up to $100 \mathrm{~nm}$, it is conceivable that scintillation yields may be limited by the physical dimensions of the NPs or by the total number of activators. The same group has also compared the effects of undoped $\mathrm{LaF}_{3}$ shell thickness on the photoluminescence $v$ s. RL of $\mathrm{LaF}_{3}: \mathrm{Eu}$ NPs (Jacobsohn et al., 2010). The undoped shells act as a passivating barrier that is transparent to both optical excitation and emission, and PL efficiency was found to increase in a roughly linear fashion as a function of overall NP size as additional shells were added. With X-ray excitation, the shells were found to increase RL efficiency up to a shell volume of roughly twice the core volume, beyond which the light yield decreased with additional shell thickness. This was attributed to the increased undoped volume decreasing the probability of radiative recombination within the Eu-doped core volume, and suggesting that the diffusion length of carriers in $\mathrm{LaF}_{3}$ to be relatively short.

Indeed, the luminescence of core-only activator-based nanoscintillators has been found to be size-dependent in some cases. One study demonstrated a considerable broadening of $\mathrm{Eu}^{3+}$ emission lines in progressively smaller $\mathrm{Gd}_{2} \mathrm{O}_{3}$ NP hosts as compared to bulk crystals, attributed to increasing crystal field fluctuations in the smaller NPs (Dujardin et al., 2010). A number of physical mechanisms potentially influencing nanoscintillators are described in the report, including structural effects, surface effects, quantum confinement, and dielectric confinement. Also shown was a significant difference in the RL spectra of bulk vs. nanoscale $\mathrm{CeF}_{3}$ samples. Intriguing scintillation behavior 
from $\mathrm{LuBO}_{3}$ :Ce nanocrystals has been reported, with a considerable dependence on the NC dimensions (Klassen et al., 2008, 2009). NC grain sizes were controlled by altering annealing temperatures, and scintillation yields were found to increase dramatically for NCs $\sim 95 \mathrm{~nm}$ in diameter, with roughly three times the intensity of NCs either $25 \mathrm{~nm}$ larger or smaller. This is in contrast to $\mathrm{LuF}_{3}: \mathrm{Ce} \mathrm{NPs}$ in the same size range, which exhibited a monotonic size dependence.

Synthesis techniques and post-synthesis processing affect the size, crystallinity, and dopant distribution of nanostructures. The role of post-synthesis annealing on NCs was recently investigated with $\mathrm{LaPO}_{4}: \mathrm{Eu}$ and $\mathrm{LaPO}_{4}: \operatorname{Pr}$ (Malyy et al., 2013), as well as $\mathrm{LuPO}_{4}$ :Ce (Vistovskyy et al., 2014). In the case of $\mathrm{LaPO}_{4}: \mathrm{Ln}$, annealing was used to increase the size of the NCs, also resulting in a change of lattice symmetry above $\sim 500^{\circ} \mathrm{C}$. The subsequent effects on excitation processes over the range of $4-40 \mathrm{eV}$ are described in some detail. Across the energy range investigated, the distinct mechanisms include intracenter excitation, charge transfer excitation, exciton or e-h pair creation, electronic excitation multiplication $\left(E>2 E_{g}\right)$, or combinations (Figure 4), and different sensitivities were shown for the two activatorsthe first stage of $\mathrm{Eu}^{3+}$ recombination involving electron capture, in contrast to hole capture by $\mathrm{Pr}^{3+}$. With $\mathrm{LuPO}_{4}$ :Ce, substantial differences in the low energy (4-25eV) VUV excitation spectrum and PL and RL decay kinetics were observed after the NCs were annealed for $2 \mathrm{~h}$ at $1200^{\circ} \mathrm{C}\left(v s\right.$. at $800^{\circ} \mathrm{C}, 300^{\circ} \mathrm{C}$, or unannealed), corresponding to an increase in the crystallite size from $3 \mathrm{~nm}$ to $35 \mathrm{~nm}$. The increased size resulted in well-defined PL emission components, dramatically enhanced band-to-band excitations above $\sim 8.7 \mathrm{eV}$, and the elimination of the slow RL decay component ascribed to surface defects. Importantly, the RL intensity for $35 \mathrm{~nm}$ NCs was found to be $\sim 100 \times$ stronger than for smaller $(<12 \mathrm{~nm}) \mathrm{NCs}$, whereas the PL intensity of both types was comparable.

The synthesis and characterization of a number of $\operatorname{Pr}^{3+}$ and $\mathrm{Ce}^{3+}$-activated garnet, silicate and oxide nanoscintillators have recently been reported, with an emphasis on their use for combined XRT/PDT, in particular their emission in the 300-400 nm range (Jung et al., 2014). The RL properties of powdered nanocrystalline samples prepared through combustion synthesis and annealing at $1200^{\circ} \mathrm{C}$ were compared with single/microcrystalline samples of similar compositions. The general composition $\left(\mathrm{Y}_{1-x} \mathrm{Pr}_{x}\right)_{3} \mathrm{Al}_{5} \mathrm{O}_{12}$ [or yttrium aluminum garnet (YAG):Pr, with an average diameter of $80 \mathrm{~nm}$ ] was found to have the highest scintillation yield of the nanoscintillators tested under $50 \mathrm{keV}$ excitation, though with a different activator concentration dependence than single crystal samples: quenching was observed for $x>1 \%$, compared to $x=$ $0.16-0.65 \%$ reported for single crystals. Somewhat surprisingly, only YAG:Pr NCs with $x=0.75,1$, and $1.5 \%$ had greater emission intensity than $\mathrm{Bi}_{4} \mathrm{Ge}_{3} \mathrm{O}_{12}$ (BGO) NCs, in stark contrast to single crystals, where $\mathrm{BGO}$ had the lowest relative intensity of the compositions investigated. Indeed, because the RL behavior of NCs is dependent on activator concentration quenching, which is in turn dependent on the NC composition, size and crystallinity, it was suggested that the properties of different preparations will likely have to be evaluated individually rather than predicted by bulk trends. The introduction of the article also provides an inclusive overview of recent progress in nanoscintillator research for biomedical applications.

Nanoscintillators that do not emit through specific activator ions are referred to as self-activated (SA), with luminescence arising from core-valence transitions, self-trapped excitons,

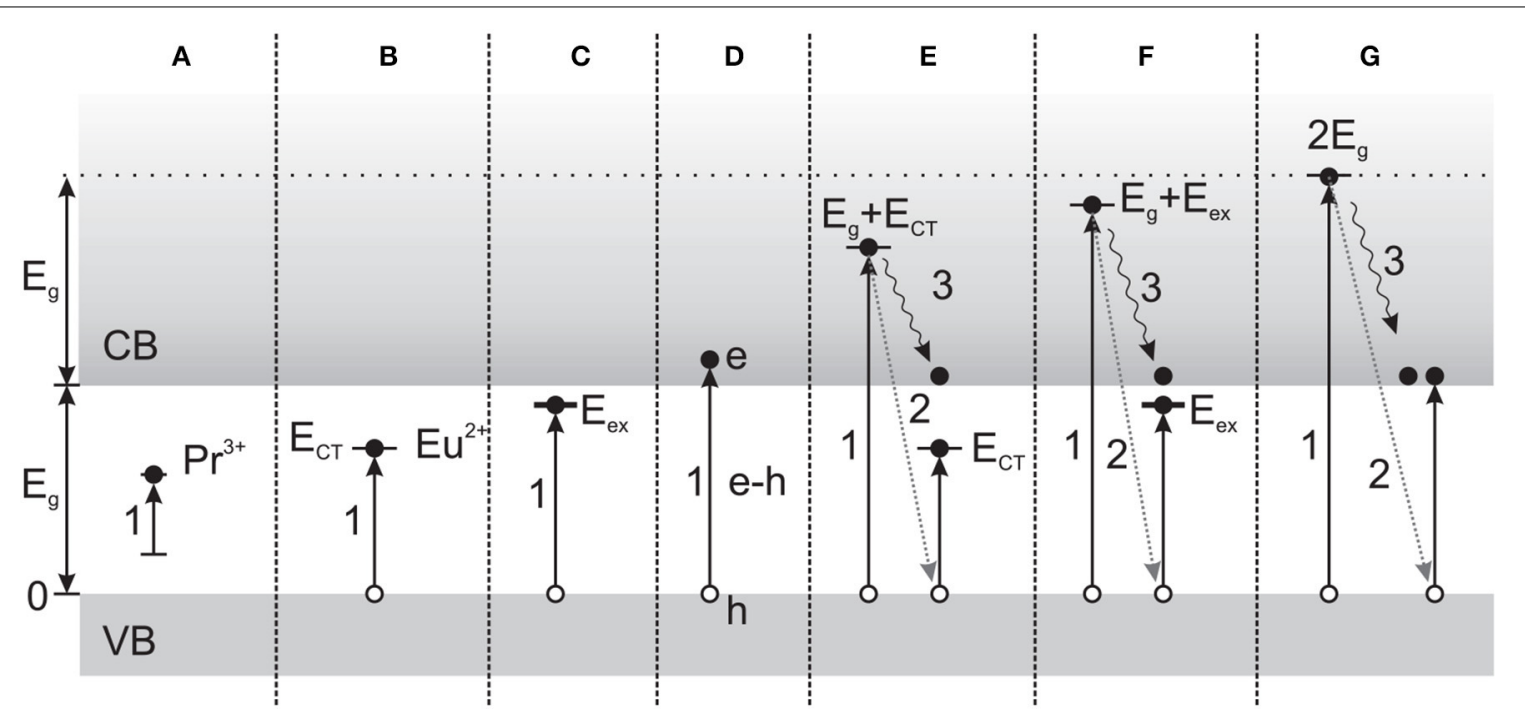

FIGURE 4 | Mechanisms of scintillation in $\mathrm{Pr}^{3+}$ or $\mathrm{Eu}^{3+}$-doped $\mathrm{LaPO}_{4}$, depending on excitation energy. (A) Intracenter (direct) excitation of $L n$ activators. (B) Excitation by charge transfer from $\mathrm{O}^{2-}$ to $\mathrm{Eu}^{3+}$. (C) Direct exciton formation. (D) Creation of e-h pairs. (E) Excitation multiplication, with secondary excitation as in (B). (F) Excitation multiplication, with secondary excitation as in (C). (G) Photons with $E>E_{g}$ can result in excitation multiplication involving the creation of secondary e-h pairs. Arrows: (1) Transition due to photon absorption. (2) Energy exchange due to inelastic scattering on valence band electrons, and (3) relaxation of primary electrons. (Reprinted with permission from Malyy et al., 2013). 
charge-transfer emissions or other mechanisms. YAG, $\mathrm{BaF}_{2}$, and $\mathrm{Y}_{2} \mathrm{O}_{3}$ are among those that have been adapted to the nanoscale, but have not yet been investigated to a large extent as SA nanoscintillators. These compositions are also routinely doped with other activators, resulting in various effects on their intrinsic luminescence.

\section{BIOCOMPATIBILITY OF LANTHANIDE-BASED MATERIALS}

Preparation of LnNP bioconjugates (covalent attachment of organic molecules of interest to the NP surface ligands) appears infrequently in the literature. The principles of bioconjugation are similar to those for QDs, Au, or other NPs, with some distinct stability and solubility concerns (Cao et al., 2012; Jiang et al., 2012). Ligand-exchanged and silicated LnNPs typically present primary amine functionalities which provide some additional versatility over carboxyl groups. Amines provide a number of conjugation routes, including routine reactions with amine, isothiocyanate, carboxyl, hydroxyl, and thiol functional groups on a molecule of interest. One study reported conjugates of phosphorylethanolamine (PEA)-stabilized $\mathrm{Eu}^{3+}$ and $\mathrm{Ce}^{3+} / \mathrm{Tb}^{3+}$-doped $\mathrm{LaF}_{3}$ by reacting the free amine of the ligand with activated biotinPEG or mPEG NHS esters, demonstrating a successful strategy for attachment of molecules through amide bond formation. The use of these conjugates was restricted to borate buffer. Biotin conjugates have also been prepared with $\mathrm{CeF}_{3}: \mathrm{Tb}$ NPs silanized using TEOS/aminopropyltriethoxysilane (APTES) (Kong et al., 2007, 2008a) and PEA-stabilized $\mathrm{Ln}^{3+}$-doped zirconia (Liu et al., 2012).

\section{SCINTILLATING NANOPARTICLE INTERACTIONS WITH DYES AND PHOTOSENSITIZERS (PSs)}

When nanoparticles are conjugated to PS molecules and irradiated with ionizing radiation, singlet oxygen yield will depend upon scintillation yield and energy transfer efficiency. Neither of these parameters has been widely reported in the literature. However, a good number of studies have investigated lanthanidedye charge transfer using light excitation, and a few studies have looked at singlet oxygen generation.

Lanthanide energy and charge transfer (ET and CT) have been extensively studied for lanthanide chelates and organic dye pairs (Selvin, 1996, 2002), and more recently in LnNPs, though most efforts have focused on sensitization of $4 f-4 f$ luminescence by $\mathrm{Ce}^{3+}, \mathrm{Yb}^{3+}$ or surface-associated organic molecules. The situation can quickly become rather complex with lanthanides whose luminescence involves the $4 f^{n}$ configuration. In these cases, magnetic dipole transitions are allowed and may have intensity of the same order of magnitude as electric dipole transitions. Additionally, some induced dipole transitions are hypersensitive to the environment of the lanthanide ion and apparently follow the selection rules of electric quadrupole transitions, leading them to be referred to as pseudo-quadrupolar transitions.

A 2004 report investigated energy transfer between porous networks of interconnected $18 \mathrm{~nm}$ YAG: $\mathrm{Ce}^{3+}$ nanocrystals (NCs) and the amine-reactive fluorescent dye tetramethylrhodamine isothiocyanate (TRITC) (Wuister et al., 2004). Glycine was used to coat the NCs, bound to the surface through the carboxylate moieties and providing terminal amines for attachment of TRITC. ET for the conjugate was demonstrated through strong emission of TRITC relative to NCs following selective excitation of the NCs, as well as the appearance of a fast initial decay of the time-resolved PL. The ET was estimated using Förster-Dexter theory, giving a "critical distance" (equivalent to $R_{0}$ ) of $7 \mathrm{~nm}$, resulting in energy transfer rates of up to $10^{8} \mathrm{~s}^{-1}$ for $\mathrm{Ce}^{3+}$ sites within $5 \mathrm{~nm}$ of the NC surface, supposed to be $\sim 90 \%$ of the total $\mathrm{Ce}^{3+}$ given the NC size.

Electrostatic complexes of $\mathrm{CePO}_{4}: \mathrm{Tb}$ nanorods and Rhodamine $\mathrm{B}$ ( $\mathrm{RhB}$ ), using $\mathrm{Ce}^{3+}$-sensitized $\mathrm{Tb}^{3+}$ emission to excite RhB, resulted in ET efficiency $\eta$ up to 0.85 as determined by ratiometric luminescence analysis (Di et al., 2010). Evidence of ET was taken by the quenching of the NP steady-state luminescence and concomitant increase in $\mathrm{RhB}$ emission with increasing amounts of RhB. Time-resolved measurements of the ${ }^{5} \mathrm{D}_{4} \rightarrow{ }^{7} \mathrm{~F}_{5}$ transition of $\mathrm{Tb}^{3+}$ also exhibited quenching but did not quantitatively agree, reporting efficiencies lower than those determined by steady-state quenching $(\eta \sim 0.7$ at the highest quenching condition).

A recent (2013) study investigated electrostatic complexes of $\mathrm{LaPO}_{4}$ :Ce nanorods and the fluorescent dye coumarin 440 (C-440) using steady-state and time-resolved PL measurements (Kar et al., 2013). The Stern-Volmer sphere of action static quenching model was applied to the steady-state quenching, and the ET efficiency estimated by the ratio of the $\mathrm{Ce}^{3+}$ fluorescence lifetimes, giving $\eta=0.24$ for an estimated 1:47 nanorod:dye ratio. ET was corroborated by an increase of the fluorescence lifetime of the dye, excited at $280 \mathrm{~nm}$, when complexed with the nanorods.

$\mathrm{X}$-ray-induced singlet oxygen production has been investigated with a handful of $\mathrm{Tb}^{3+}$-activated oxide and fluoride nanoscintillators coupled with grafted or encapsulated photosensitizers. In one study, 11-aminoundecanoic acid-coated $\mathrm{La}_{0.8} \mathrm{~Tb}_{0.2} \mathrm{~F}_{3}$ NPs were mixed with the water-soluble photosensitizer meso-tetra(4-carboxyphenyl) porphine (MTCP) (Liu et al., 2008), which resulted in an increase in the quenching rate of the anthracenedipropionic acid (ADPA) singlet oxygen probe compared to PS alone under $250 \mathrm{keV}$ X-ray irradiation at $44 \mathrm{cGy} / \mathrm{min}$. Singlet oxygen production was demonstrated using $\left(\mathrm{Gd}_{0.5} \mathrm{~Tb}_{0.5}\right)_{2} \mathrm{O}_{3}$ NPs with PS-encapsulating polysiloxane shells (Seve et al., 2012). The photosensitizer 5-(4-carboxyphenyl)10,15,20-triphenyl-chlorin (TPC) was first conjugated to APTES before reaction of the TPC-APTES with TEOS for shell formation, resulting in varied amounts of covalently bound TPC embedded within the shell. In this case, increasing concentrations of encapsulated TPC resulted in quenching of the TPC PL (directly excited at $414 \mathrm{~nm}$ ) as well as singlet oxygen production (directly detected through $1270 \mathrm{~nm}$ phosphorescence). This result was attributed to migration of excitation energy between TPC molecules terminated at static quenching sites, with a model developed to support the data.

Recently, energy transfer mechanisms and singlet oxygen production under optical and $\mathrm{X}$-ray irradiation were studied using a similar system consisting of Gd-free $\mathrm{Tb}_{2} \mathrm{O}_{3}$ NPs with the photosensitizer 5-(4-carboxyphenyl)-10,15,20-triphenyl 
porphyrin (TPP) grafted to the polysiloxane shells after rather than during their formation (Bulin et al., 2013). The NPs and NP-PS were used in DEG solution. Upon excitation at $300 \mathrm{~nm}$ (primarily resulting in $4 \mathrm{f}^{8} \rightarrow 4 f^{7} 5 \mathrm{~d}^{1}$ transitions in $\mathrm{Tb}^{3+}$ ), a concurrent decrease of the $\mathrm{Tb}^{3+}$ lifetimes (measured at $545 \mathrm{~nm}$ ) and appearance of long PL lifetimes of the grafted PS (measured at $650 \mathrm{~nm}$ ) were taken to be indicative of excited $\mathrm{Tb}^{3+}$-PS nonradiative energy transfer. Interestingly, the polysiloxane layer was implicated in the appearance of a broad emission component from the NPs with a peak $\sim 425 \mathrm{~nm}$ that was also involved in efficient, fast energy transfer to TPP under optical excitation, but did not appear under X-ray excitation. Singlet oxygen yields under $44 \mathrm{kV}$ X-ray excitation (from a tungsten anode, providing a dose rate of $5.4 \mathrm{mGy} / \mathrm{s}$ ) were evaluated with the chemical probes singlet oxygen sensor green (SOSG) and $3^{\prime}$-p-(aminophenyl) fluorescein (APF). SOSG showed a steady increase in signal with both PS alone and NP-PS, with the NP-PS showing a relative increase for irradiation times $>10 \mathrm{~min}$. The APF probe corroborated the formation of singlet oxygen by the NP-PS system, supported by competitive quenching of singlet oxygen by addition of $\mathrm{NaN}_{3}$.

A small number of nanoscintillator-PS conjugate systems have demonstrated measurable enhancements of X-ray irradiation in cancer cell lines. In one study, commercially available $\mathrm{Y}_{2} \mathrm{O}_{3}$ NPs were modified with 2-chloroethylphosphonic acid (2-CEP) ligands, which were used to form thioether linkages to fragments of the HIV-1 TAT cell-penetrating/nuclear targeting peptide bound to the PS psoralen (Scaffidi et al., 2011). A small but significant downward trend in the growth of PS3 prostate cancer cells with 2 Gy of $160 \mathrm{kVp}$ or $320 \mathrm{kVp}$ X-rays was seen as a function of particle dose. Another study reported activity of a terbium-doped gadolinium oxysulfide-Photofrin II mixture against glioblastoma cells irradiated with $120 \mathrm{kVp}$ diagnostic X-rays. Radiation alone produced $20 \%$ cell suppression, and radiation plus the NP-PS combination over $90 \%$ suppression. Interestingly, the particles alone (without Photofrin) protected the cells against X-irradiation.

A theoretical paper investigated the conditions required for a nanoscintillator-photosensitizer conjugate system to produce therapeutically-relevant results, using physical parameters including nanoparticle uptake into cells, enhancement of radiation dose, scintillation light yields, and energy transfer efficiencies (Morgan et al., 2009). These parameters were used to estimate the overall singlet oxygen yield of a NP-PS system with X-ray irradiation. As singlet oxygen is considered to be the primary effector of PDT, its production was taken to be indicative of the potential of conjugates to damage malignant tissue through PS activation. Overall singlet oxygen production $\Phi_{1 \mathrm{O}_{2}}$ was determined from the product of the scintillation yield $\varphi_{s}$, characteristic of the material and given in photons per $\mathrm{MeV}$ of absorbed radiation, the NP-PS energy transfer efficiency $\varphi_{E T}$, and the PS singlet oxygen yield $\varphi_{p}$. For an extremely generous value of $\varphi_{s}>10^{5}$ photons/MeV (derived from the energy output of bulk crystals of hygroscopic $\mathrm{LuI}_{3}: \mathrm{Ce}^{3+}$ ) and somewhat generous values of $\varphi_{E T}=0.75$ and $\varphi_{p}=0.89$, and using the relative X-ray absorption of the NPs, it was determined that to deliver the "Niedre killing dose" of singlet oxygen (reduction of a cell population to 1/e fraction, based on in vitro measurements of OCI-AML5 leukemia) (Niedre et al., 2002, 2003), only X-ray energies below $\sim 200 \mathrm{keV}$ (with peak efficiency $\sim 50 \mathrm{keV}$ ) would be effective for reasonable total radiation doses. These results suggest that it would be difficult to produce a dramatic outcome with PDT effects alone.

It has been established that the efficacy of PDT in vivo depends on three primary mechanisms: direct tumor-cell killing; damage to tumor vasculature; and provocation of an immune response (in contrast to the immunosuppressive effects of radiotherapy and chemotherapy (Dolmans et al., 2003). If these observations hold true for nanoscintillator-photosensitizer systems, it is conceivable that the optimal targeting and cell-level distributions of such systems may be different from those that rely solely on radiation dose enhancement by nanoparticles (which are most effective in close proximity to cell nuclei). It would also be reasonable to expect that preserving the amphiphilicity of bioconjugated photosensitizers might be beneficial, as the tendency to associate with lipid membranes is known to be a key factor in the activity of free PS molecules (Kessel et al., 1987; Jori and Reddi, 1993). Whether active targeting to tumors improves nanoparticle accumulation in human cancers and/or treatment outcomes remains debatable. There are certainly circumstances in which passive accumulation is insufficient due to the physical properties of the tumor, but the ideal target for human tumors has not been well established (Kobayashi et al., 2013; Moghimi and Farhangrazi, 2014; Nichols and Bae, 2014).

\section{OTHER ALTERNATIVES: CHEMOTHERAPY-NANOPARTICLE CONSTRUCTS}

A large number of nanoparticle conjugates to chemotherapeutic agents have been reported, but few of these have been used for radiosensitization. This is somewhat surprising, since traditional chemotherapeutic agents often act as radiosensitizers, and probably just reflects the emerging state of the field. A few reports have targeted metal nanoparticles to cells or tumors using molecules that play an active role in destroying the target cells. In one study, radioresistant melanoma cells were exposed to Au nanorods conjugated to the RGD peptide (Xu et al., 2012). Exposure to MV $\mathrm{X}$-rays decreased integrin expression and rendered the cells susceptible to radiation-induced apoptosis.

Another study showed that nanoparticle preparations of epithelial growth factor receptor (EGFR) antisense oligonucleotides radiosensitized SCCVII murine squamous carcinoma cells (Xu et al., 2012). However, the nanoparticles themselves were a delivery vehicle only, so no synergy was being sought between the particles and their cargo.

In another approach, doxorubicin conjugated to DNA-coated large Au nanoparticles was loaded into MCF-7 breast cancer cells (Starkewolf et al., 2013). Irradiation with X-rays improved cell inhibition by $33 \%$ at 10 Gy relative to Dox alone or Au nanoparticles alone. The authors attributed this observation to release of Dox by the radiation.

\section{SUMMARY AND CONCLUSION}

Dense inorganic nanoparticles show considerable promise for dose enhancement of radiation therapy and enabling synergistic 
co-treatments. Gold nanoparticles are the most studied, though are not yet in the clinic for radiation therapy. Research efforts are underway to increase the efficiency of nanoparticle-based treatments, including physical and chemical optimization of nanoparticles, improved targeting such that total doses can be reduced, and combining ionizing radiation with other therapeutic modalities. Pre-sensitization of tumors with localized heating resulting from illumination of $\mathrm{Au}$ nanostructures with infrared light (photothermal therapy) has shown encouraging results. A number of less expensive alternatives to $\mathrm{Au}$ have been produced, but have not been subject to the same level of research activity. Oxides and selenides of $\mathrm{Pt}$ and $\mathrm{Bi}$ have been shown to provide radiation dose enhancement, while those of Gd and Fe also enable magnetism-based imaging, guidance and hyperthermia.

Nanoscintillators consist of a broad class of nanostructures that emit light ranging from the ultraviolet to the infrared upon excitation by ionizing radiation, with spectra that depend primarily on composition. Energy transfer from excited state nanoscintillators to surface-attached photosensitizer molecules allows such a system to improve upon the issue of tissue transmittance encountered with typical PDT, combined with the dose enhancement provided by the dense nanoparticles. If the emitted light is of an appropriate wavelength to be absorbed by photosensitizer molecules, nanoscintillator-photosensitizer bioconjugates have the potential to improve upon the issue of tissue transmittance with typical PDT. Such systems have only recently been reported, but represent another distinct class for combined therapy that requires only ionizing radiation. As these systems have thus far only been studied in vitro, and cover many possible material compositions and drug varieties, it is difficult to reach definitive conclusions about their advantages and disadvantages compared to Au. While the raw materials are less expensive than $\mathrm{Au}$ in general, the particles tend to be less than half as dense as $\mathrm{Au}$, and provide lower enhancement factors. While the surface chemistry of $\mathrm{Au}$ is well established and reliable, oxide and fluoride nanoscintillators have known colloidal stability issues. Certainly, if XRT and PDT effects are determined to be synergistic, such systems may soon become a viable option for nanotherapeutics.

Despite the substantial progress in nanoparticle-assisted therapies in recent years, nanoscale radiosensitization effects have not yet been studied in great detail. Further understanding of the essential principles and interactions will help establish the legitimacy of new undertakings in the burgeoning field of nanomedicine, where clinical applications are just beginning to emerge.

While a good deal of preclinical data on GNRT is available, there are not yet clinical trials in the U.S. Two types of $\mathrm{Au}$ nanoparticles have been FDA approved for cancer trials: Au-tumor necrosis factor conjugates (clinicaltrials.gov, NCT00356980) and $\mathrm{Au}$ nanoshells for photothermal therapy (AuroLase, currently recruiting, NCT01679470 and NCT00848042 for lung cancer and head and neck cancer, respectively). Hafnium oxide particles are in clinical trials as radiation enhancers (NCT01433068, currently recruiting; drug name NBTXR3).

\section{ACKNOWLEDGMENTS}

This work was funded by the CIHR Operating Grant MOP133500. Jay L. Nadeau's salary support was provided by the Canada Research Chairs. Devesh Bekah's stipend was provided by the NSERC CREATE Medical Physics Research Training Network (MPRTN).

\section{REFERENCES}

Alqathami, M., Blencowe, A., Yeo, U., Franich, R., Doran, S., Qiao, G., et al. (eds.). (2013). Enhancement of radiation effects by bismuth oxide nanoparticles for kilovoltage $\mathrm{x}$-ray beams: a dosimetric study using a novel multi-compartment 3D radiochromic dosimeter. J. Phys. Conf. Ser. 444:012025. doi: 10.1088/17426596/444/1/012025

Atkinson, R. L., Zhang, M., Diagaradjane, P., Peddibhotla, S., Contreras, A., Hilsenbeck, S. G., et al. (2010). Thermal enhancement with optically activated gold nanoshells sensitizes breast cancer stem cells to radiation therapy. Sci. Transl. Med. 2:55ra79. doi: 10.1126/scitranslmed.3001447

Babaei, M., and Ganjalikhani, M. (2014). The potential effectiveness of nanoparticles as radio sensitizers for radiotherapy. Bioimpacts 4, 15-20. doi: 10.5681/bi.2014.003

Brun, E., Sanche, L., and Sicard-Roselli, C. (2009). Parameters governing gold nanoparticle X-ray radiosensitization of DNA in solution. Colloids Surf B Biointerfaces 72, 128-134. doi: 10.1016/j.colsurfb.2009.03.025

Bulin, A.-L., Truillet, C., Chouikrat, R., Lux, F., Frochot, C., Amans, D., et al. (2013). X-ray-induced singlet oxygen activation with nanoscintillatorcoupled porphyrins. J. Phys. Chem. C 117, 21583-21589. doi: 10.1021/jp4 077189

Bünzli, J.-C. G., and Eliseeva, S. V. (2010). Basics of lanthanide photophysics. Lanthanide Luminescence 7, 1-45. doi: 10.1007/4243_2010_3

Butterworth, K. T., McMahon, S. J., Currell, F. J., and Prise, K. M. (2012). Physical basis and biological mechanisms of gold nanoparticle radiosensitization. Nanoscale 4, 4830-4838. doi: 10.1039/c2nr31227a

Cao, P., Tong, L., Hou, Y., Zhao, G., Guerin, G., Winnik, M. A., et al. (2012). Improving lanthanide nanocrystal colloidal stability in competitive aqueous buffer solutions using multivalent PEG-phosphonate ligands. Langmuir 28, 12861-12870. doi: 10.1021/la302690h

Chattopadhyay, N., Cai, Z. L., Kwon, Y. L., Lechtman, E., Pignol, J. P., and Reilly, R. M. (2013). Molecularly targeted gold nanoparticles enhance the radiation response of breast cancer cells and tumor xenografts to X-radiation. Breast Cancer Res. Treat. 137, 81-91. doi: 10.1007/s10549-012-2338-4

Chen, W., and Zhang, J. (2006). Using nanoparticles to enable simultaneous radiation and photodynamic therapies for cancer treatment. J. Nanosci. Nanotechnol. 6, 1159-1166. doi: 10.1166/jnn.2006.327

Cheng, S. H., and Lo, L. W. (2011). Inorganic nanoparticles for enhanced photodynamic cancer therapy. Curr. Drug Discov. Technol. 8, 250-268. doi: $10.2174 / 157016311796798982$

Cho, S. H., Jones, B. L., and Krishnan, S. (2009). The dosimetric feasibility of gold nanoparticle-aided radiation therapy (GNRT) via brachytherapy using low-energy gamma-/x-ray sources. Phys. Med. Biol. 54, 4889-4905. doi: 10.1088/0031-9155/54/16/004

Di, W., Li, J., Shirahata, N., and Sakka, Y. (2010). An efficient and biocompatible fluorescence resonance energy transfer system based on lanthanide-doped nanoparticles. Nanotechnology 21:455703. doi: 10.1088/09574484/21/45/455703

Diagaradjane, P., Shetty, A., Wang, J. C., Elliott, A. M., Schwartz, J., Shentu, S., et al. (2008). Modulation of in vivo tumor radiation response via gold nanoshell-mediated vascular-focused hyperthermia: characterizing an integrated antihypoxic and localized vascular disrupting targeting strategy. Nano Lett. 8, 1492-1500. doi: 10.1021/nl080496z

Dolmans, D. E., Fukumura, D., and Jain, R. K. (2003). Photodynamic therapy for cancer. Nat. Rev. Cancer 3, 380-387. doi: 10.1038/nrc1071

Dorenbos, P. (2000). The $5 \mathrm{~d}$ level positions of the trivalent lanthanides in inorganic compounds. J. Lumin. 91, 155-176. doi: 10.1016/S0022-2313(00) 00229-5

Dujardin, C., Amans, D., Belsky, A., Chaput, F., Ledoux, G., and Pillonnet, A. (2010). Luminescence and scintillation properties at the nanoscale. IEEE Trans. Nucl. Sci. 57, 1348-1354. doi: 10.1109/TNS.2009.2035697 
El-Sayed, I. H., Huang, X., and El-Sayed, M. A. (2006). Selective laser photothermal therapy of epithelial carcinoma using anti-EGFR antibody conjugated gold nanoparticles. Cancer Lett. 239, 129-135. doi: 10.1016/j.canlet.2005.07.035

Geng, F., Song, K., Xing, J. Z., Yuan, C. Z., Yan, S., Yang, Q. F., et al. (2011). Thioglucose bound gold nanoparticles enhance radio-cytotoxic targeting of ovarian cancer. Nanotechnology 22:285101. doi: 10.1088/0957-4484/22/28/285101

Giustini, A. J., Petryk, A. A., and Hoopes, P. J. (2011). Comparison of microwave and magnetic nanoparticle hyperthermia radiosensitization in murine breast tumors. Proc. SPIE 7901. doi: 10.1117/12.876515

Gobin, A. M., Lee, M. H., Halas, N. J., James, W. D., Drezek, R. A., and West, J. L. (2007). Near-infrared resonant nanoshells for combined optical imaging and photothermal cancer therapy. Nano Lett. 7, 1929-1934. doi: 10.1021/nl07 $0610 y$

Griffin, R. J., Okajima, K., Barrios, B., and Song, C. W. (1996). Mild temperature hyperthermia combined with carbogen breathing increases tumor partial pressure of oxygen (pO2) and radiosensitivity. Cancer Res. 56, 5590-5593.

Guss, P., Guise, R., Yuan, D., Mukhopadhyay, S., O’Brien, R., Lowe, D., et al. (2013). Lanthanum halide nanoparticle scintillators for nuclear radiation detection. J. Appl. Phys. 113:064303. doi: 10.1063/1.4790867

Hainfeld, J. F., Dilmanian, F. A., Zhong, Z., Slatkin, D. N., Kalef-Ezra, J. A., and Smilowitz, H. M. (2010). Gold nanoparticles enhance the radiation therapy of a murine squamous cell carcinoma. Phys. Med. Biol. 55, 3045-3059. doi: 10.1088/0031-9155/55/11/004

Hainfeld, J. F., Slatkin, D. N., and Smilowitz, H. M. (2004). The use of gold nanoparticles to enhance radiotherapy in mice. Phys. Med. Biol. 49, N309-N315. doi: 10.1088/0031-9155/49/18/N03

Herold, D. M., Das, I. J., Stobbe, C. C., Iyer, R. V., and Chapman, J. D. (2000). Gold microspheres: a selective technique for producing biologically effective dose enhancement. Int. J. Radiat. Biol. 76, 1357-1364. doi: $10.1080 / 09553000050151637$

Hossain, M., and Su, M. (2012). Nanoparticle location and material dependent dose enhancement in X-ray radiation therapy. J. Phys. Chem. C. 116, 23047-23052. doi: 10.1021/jp306543q

Huang, P., Bao, L., Zhang, C. L., Lin, J., Luo, T., Yang, D. P., et al. (2011). Folic acid-conjugated Silica-modified gold nanorods for X-ray/CT imaging-guided dual-mode radiation and photo-thermal therapy. Biomaterials 32, 9796-9809. doi: 10.1016/j.biomaterials.2011.08.086

Huang, X., El-Sayed, I. H., Qian, W., and El-Sayed, M. A. (2006). Cancer cell imaging and photothermal therapy in the near-infrared region by using gold nanorods. J. Am. Chem. Soc. 128, 2115-2120. doi: 10.1021/ja057254a

Jacobsohn, L. G., Sprinkle, K. B., Kucera, C. J., James, T. L., Roberts, S. A., Qian, H., et al. (2010). Synthesis, luminescence and scintillation of rare earth doped lanthanum fluoride nanoparticles. Opt. Mater. 33, 136-140. doi: 10.1016/j.optmat.2010.07.025

Jacobsohn, L. G., Sprinkle, K. B., Roberts, S. A., Kucera, C. J., James, T. L., Yukihara, E. G., et al. (2011). Fluoride nanoscintillators. J. Nanomater. 2011:523638. doi: $10.1155 / 2011 / 523638$

Jain, S., Hirst, D. G., and O’Sullivan, J. M. (2012). Gold nanoparticles as novel agents for cancer therapy. Br. J. Radiol. 85, 101-113. doi: 10.1259/bjr/59448833

Jelveh, S., and Chithrani, D. B. (2011). Gold Nanostructures as a platform for combinational therapy in future cancer therapeutics. Cancers 3, 1081-1110. doi: 10.3390/cancers3011081

Jiang, G., Pichaandi, J., Johnson, N. J. J., Burke, R. D., and van Veggel, F. C. J. M. (2012). An effective polymer cross-linking strategy to obtain stable dispersions of upconverting NaYF4 nanoparticles in buffers and biological growth media for biolabeling applications. Langmuir 28, 3239-3247. doi: 10.1021/la20 $4020 \mathrm{~m}$

Jori, G., and Reddi, E. (1993). The role of lipoproteins in the delivery of tumourtargeting photosensitizers. Int. J. Biochem. 25, 1369-1375. doi: 10.1016/0020711X(93)90684-7

Jung, J. Y., Hirata, G. A., Gundiah, G., Derenzo, S., Wrasidio, W., Kesari, S., et al. (2014). Identification and development of nanoscintillators for biotechnology applications. J. Lumin. 154, 569-577. doi: 10.1016/j.jlumin.2014.05.040

Kampinga, H. H. (2006). Cell biological effects of hyperthermia alone or combined with radiation or drugs: a short introduction to newcomers in the field. Int. J. Hyperthermia 22, 191-196. doi: 10.1080/02656730500532028

Kar, A., Kundu, A., Bhattacharyya, S., Mandal, S., and Patra, A. (2013). Lanthanide based resonance energy transfer (LRET) between Ce-doped LaPO4 nanorods and coumarin 440 dye. RSC Adv. 3, 13372-13380. doi: 10.1039/c3ra40728d
Kessel, D., Thompson, P., Saatio, K., and Nantwi, K. D. (1987). Tumor localization and photosensitization by sulfonated derivatives of tetraphenylporphine. Photochem. Photobiol. 45, 787-790. doi: 10.1111/j.1751-1097.1987.tb07883.x

Khoei, S., Mahdavi, S. R., Fakhimikabir, H., Shakeri-Zadeh, A., and Hashemian, A. (2014). The role of iron oxide nanoparticles in the radiosensitization of human prostate carcinoma cell line DU145 at megavoltage radiation energies. Int. J. Radiat. Biol. 90, 351-356. doi: 10.3109/09553002.2014.888104

Klassen, N. V., Kedrov, V. V., Kurlov, V. N., Ossipyan, Y. A., Shmurak, S. Z., Shmyt'ko, I. M., et al. (2008). Advantages and problems of nanocrystalline scintillators. IEEE Trans. Nucl. Sci. 55, 1536-1541. doi: 10.1109/TNS.2008.924050

Klassen, N. V., Kedrov, V. V., Ossipyan, Y. A., Shmurak, S. Z., Shmyt'ko, I. M., Krivko, O. A., et al. (2009). Nanoscintillators for microscopic diagnostics of biological and medical objects and medical therapy. IEEE Trans. Nanobiosci. 8, 20-32. doi: 10.1109/TNB.2009.2016551

Klein, S., Sommer, A., Distel, L. V. R., Hazemann, J.-L., Kroner, W., Neuhuber, W., et al. (2014). Superparamagnetic iron oxide nanoparticles as novel X-ray enhancer for low-dose radiation therapy. J. Phys. Chem. B 118, 6159-6166. doi: $10.1021 /$ jp5026224

Kobayashi, H., Watanabe, R., and Choyke, P. L. (2013). Improving conventional enhanced permeability and retention (EPR) effects; what is the appropriate target? Theranostics 4, 81-89. doi: 10.7150/thno.7193

Kobayashi, K., Usami, N., Porcel, E., Lacombe, S., and Le Sech, C. (2010). Enhancement of radiation effect by heavy elements. Mutat. Res. 704, 123-131. doi: 10.1016/j.mrrev.2010.01.002

Kong, D., Yang, P., Wang, Z., Chai, P., Huang, S., Lian, H., et al. (2008a) Mesoporous silica coated $\mathrm{CeF} 3: \mathrm{Tb} 3+$ particles for drug release. J. Nanomater. 2008:6. doi: 10.1155/2008/312792

Kong, D. Y., Wang, Z. L., Lin, C. K., Quan, Z. W., Li, Y. Y., Li, C. X., et al. (2007). Biofunctionalization of $\mathrm{CeF}(3): \mathrm{Tb}(3+)$ nanoparticles. Nanotechnology 18:075601. doi: 10.1088/0957-4484/18/7/075601

Kong, T., Zeng, J., Wang, X. P., Yang, X. Y., Yang, J., McQuarrie, S., et al. (2008b). Enhancement of radiation cytotoxicity in breast-cancer cells by localized attachment of gold nanoparticles. Small 4, 1537-1543. doi: 10.1002/smll.2007 00794

Kortov, V. S. (2010). Nanophosphors and outlooks for their use in ionizing radiation detection. Radiat. Meas. 45, 512-515. doi: 10.1016/j.radmeas.2009. 11.009

Le Duc, G., Miladi, I., Alric, C., Mowat, P., Bräuer-Krisch, E., Bouchet, A., et al. (2011). Toward an image-guided microbeam radiation therapy using gadolinium-based nanoparticles. ACS Nano 5, 9566-9574. doi: $10.1021 / \mathrm{nn} 202797 \mathrm{~h}$

Lempicki, A., Wojtowicz, A. J., and Berman, E. (1993). Fundamental limits of scintillator performance. Nucl. Instrum. Methods Phys. Res. A 333, 304-311. doi: 10.1016/0168-9002(93)91170-R

Létant, S. E., and Wang, T. F. (2006). Semiconductor quantum dot scintillation under $\gamma$-ray irradiation. Nano Lett. 6, 2877-2880. doi: 10.1021/nl06 20942

Leung, M. K. K., Chow, J. C. L., Chithrani, B. D., Lee, M. J. G., Oms, B., and Jaffray, D. A. (2011). Irradiation of gold nanoparticles by x-rays: monte carlo simulation of dose enhancements and the spatial properties of the secondary electrons production. Med. Phys. 38, 624-631. doi: 10.1118/1.3539623

Liu, Y., Chen, W., Wang, S., and Joly, A. G. (2008). Investigation of water-soluble $\mathrm{x}$-ray luminescence nanoparticles for photodynamic activation. Appl. Phys. Lett. 92, 043901. doi: 10.1063/1.2835701

Liu, Y., Zhou, S., Tu, D., Chen, Z., Huang, M., Zhu, H., et al. (2012). Amine-Functionalized lanthanide-doped zirconia nanoparticles: optical spectroscopy, time-resolved fluorescence resonance energy transfer biodetection, and targeted imaging. J. Am. Chem. Soc. 134, 15083-15090. doi: 10.1021/ja3 $06066 \mathrm{a}$

Low, P. S., Henne, W. A., and Doorneweerd, D. D. (2008). Discovery and development of folic-acid-based receptor targeting for imaging and therapy of cancer and inflammatory diseases. Acc. Chem. Res. 41, 120-129. doi: 10.1021/ar7000815

Malyy, T. S., Vistovskyy, V. V., Khapko, Z. A., Pushak, A. S., Mitina, N. E., Zaichenko, A. S., et al. (2013). Recombination luminescence of LaPO4-Eu and LaPO4-Pr nanoparticles. J. Appl. Phys. 113, 224305. doi: 10.1063/1.48 08797

McKigney, E. A., Del Sesto, R. E., Jacobsohn, L. G., Santi, P. A., Muenchausen, R. E., Ott, K. C., et al. (2007a). Nanocomposite scintillators for radiation detection 
and nuclear spectroscopy. Nucl. Instrum. Methods Phys. Res. A 579, 15-18. doi: 10.1016/j.nima.2007.04.004

McKigney, E. A., Muenchausen, R. E., Cooke, D. W., Del Sesto, R. E., Gilbertson, R. D., Bacrania, M. K., et al. (eds.). (2007b). $\mathrm{LaF}_{3}$ :Ce nanocomposite scintillator for gamma-ray detection. Proc. SPIE6706. doi: 10.1117/12.737364

McMahon, S. J., Mendenhall, M. H., Jain, S., and Currell, F. (2008). Radiotherapy in the presence of contrast agents: a general figure of merit and its application to gold nanoparticles. Phys. Med. Biol. 53, 5635-5651. doi: 10.1088/00319155/53/20/005

Miladi, I., Duc, G. L., Kryza, D., Berniard, A., Mowat, P., Roux, S., et al. (2013). Biodistribution of ultra small gadolinium-based nanoparticles as theranostic agent: application to brain tumors. J. Biomater. Appl. 28, 385-394. doi: $10.1177 / 0885328212454315$

Moghimi, S. M., and Farhangrazi, Z. S. (2014). Just so stories: the random acts of anti-cancer nanomedicine performance. Nanomedicine. doi: 10.1016/j.nano.2014.04.011. [Epub ahead of print].

Moretti, F., Patton, G., Belsky, A., Fasoli, M., Vedda, A., Trevisani, M., et al. (2014). Radioluminescence sensitization in scintillators and phosphors: trap engineering and modeling. J. Phys. Chem. C 118, 9670-9676. doi: 10.1021/jp50 $1717 \mathrm{z}$

Morgan, N. Y., Kramer-Marek, G., Smith, P. D., Camphausen, K., and Capala, J. (2009). Nanoscintillator conjugates as photodynamic therapy-based radiosensitizers: calculation of required physical parameters. Radiat. Res. 171, 236-244. doi: $10.1667 /$ RR1470.1

Moses, W. W., and Derenzo, S. E. (1989). Cerium fluoride, a new fast, heavy scintillator. IEEE Trans. Nucl. Sci. 36, 173-176. doi: 10.1109/23.34428

Moses, W. W., and Derenzo, S. E. (1990). The scintillation properties of ceriumdoped lanthanum fluoride. Nucl. Instrum. Methods Phys. Res. A 299, 51-56. doi: 10.1016/0168-9002(90)90746-S

Moses, W. W., Derenzo, S. E., Weber, M. J., Ray-Chaudhuri, A. K., and Cerrina, F. (1994). Scintillation mechanisms in cerium fluoride. J. Lumin. 59, 89-100. doi 10.1016/0022-2313(94)90026-4

Ngwa, W., Makrigiorgos, G. M., and Berbeco, R. I. (2010). Applying gold nanoparticles as tumor-vascular disrupting agents during brachytherapy: estimation of endothelial dose enhancement. Phys. Med. Biol. 55:6533. doi: 10.1088/0031$9155 / 55 / 21 / 013$

Nichols, J. W., and Bae, Y. H. (2014). EPR: evidence and fallacy. J. Control. Release 190C, 451-464. doi: 10.1016/j.jconrel.2014.03.057

Niedre, M. J., Secord, A. J., Patterson, M. S., and Wilson, B. C. (2003). In vitro tests of the validity of singlet oxygen luminescence measurements as a dose metric in photodynamic therapy. Cancer Res. 63, 7986-7994.

Niedre, M., Patterson, M. S., and Wilson, B. C. (2002). Direct near-infrared luminescence detection of singlet oxygen generated by photodynamic therapy in cells in vitro and tissues in vivo. Photochem. Photobiol. 75, 382-391. doi: 10.1562/0031-8655(2002)0750382DNILDO2.0.CO2

Rahman, W. N., Bishara, N., Ackerly, T., He, C. F., Jackson, P., Wong, C., et al. (2009). Enhancement of radiation effects by gold nanoparticles for superficial radiation therapy. Nanomedicine 5, 136-142. doi: 10.1016/j.nano.2009. 01.014

Razzak, R., Zhou, J., Yang, X., Pervez, N., Bedard, E. L., Moore, R. B., et al. (2013). The biodistribution and pharmacokinetic evaluation of choline-bound gold nanoparticles in a human prostate tumor xenograft model. Clin. Invest. Med. 36, E133-E142.

Robbins, D. J. (1980). On predicting the maximum efficiency of phosphor systems excited by ionizing radiation. J. Electrochem. Soc. 127, 2694-2702. doi: $10.1149 / 1.2129574$

Rodnyi, P., Melchakov, E., Zakharov, N., Munro, I., and Hopkirk, A. (1995). Fast luminescence of cerium doped lanthanum fluoride. J. Lumin. 65, 85-89. doi 10.1016/0022-2313(95)00055-U

Scaffidi, J. P., Gregas, M. K., Lauly, B., Zhang, Y., and Vo-Dinh, T. (2011). Activity of psoralen-functionalized nanoscintillators against cancer cells upon X-ray excitation. ACS Nano 5, 4679-4687. doi: 10.1021/nn200511m

Selvin, P. R. (1996). Lanthanide-based resonance energy transfer. IEEE J. Sel. Top. Quantum Electron. 2, 1077-1087. doi: 10.1109/2944.577339

Selvin, P. R. (2002). Principles and biophysical applications of lanthanidebased probes. Annu. Rev. Biophys. Biomol. Struct. 31, 275-302. doi: 10.1146/annurev.biophys.31.101101.140927

Seve, A., Couleaud, P., Lux, F., Tillement, O., Arnoux, P., Andre, J.-C., et al. (2012). Long-distance energy transfer photosensitizers arising in hybrid nanoparticles leading to fluorescence emission and singlet oxygen luminescence quenching. Photochem. Photobiol. Sci. 11, 803-811. doi: 10.1039/c2pp0 $5324 \mathrm{a}$

Song, C. W., Shakil, A., Osborn, J. L., and Iwata, K. (2009). Tumour oxygenation is increased by hyperthermia at mild temperatures. Int. J. Hyperthermia 25, 91-95. doi: 10.1080/02656730902744171

Song, K., Xu, P., Meng, Y. D., Geng, F., Li, J., Li, Z., et al. (2013). Smart gold nanoparticles enhance killing effect on cancer cells. Int. J. Oncol. 42, 597-608. doi: 10.3892/ijo.2012.1721

Starkewolf, Z. B., Miyachi, L., Wong, J., and Guo, T. (2013). X-ray triggered release of doxorubicin from nanoparticle drug carriers for cancer therapy. Chem. Commun. 49, 2545-2547. doi: 10.1039/c3cc38100e

Su, X. Y., Liu, P. D., Wu, H., and Gu, N. (2014). Enhancement of radiosensitization by metal-based nanoparticles in cancer radiation therapy. Cancer Biol. Med. 11, 86-91. doi: 10.7497/j.issn.2095-3941.2014. 02.003

van Dam, G. M., Themelis, G., Crane, L. M., Harlaar, N. J., Pleijhuis, R. G., Kelder, W., et al. (2011). Intraoperative tumor-specific fluorescence imaging in ovarian cancer by folate receptor-alpha targeting: first in-human results. Nat. Med. 17, 1315-1319. doi: 10.1038/nm.2472

Van den Heuvel, F., Locquet, J. P., and Nuyts, S. (2010). Beam energy considerations for gold nano-particle enhanced radiation treatment. Phys. Med. Biol. 55, 4509-4520. doi: 10.1088/0031-9155/55/16/S06

van der Zee, J., González, D., van Rhoon, G. C., van Dijk, J. D. P., van Putten, W. L. J., and Hart, A. A. M. (2000). Comparison of radiotherapy alone with radiotherapy plus hyperthermia in locally advanced pelvic tumours: a prospective, randomised, multicentre trial. Lancet 355, 1119-1125. doi: 10.1016/S01406736(00)02059-6

Verma, J., Lal, S., and Van Noorden, C. J. (2014). Nanoparticles for hyperthermic therapy: synthesis strategies and applications in glioblastoma. Int. J. Nanomedicine 9, 2863-2877. doi: 10.2147/IJN.S57501

Vernon, C. C., Hand, J. W., Field, S. B., Machin, D., Whaley, J. B., van der Zee, J., et al. (1996). Radiotherapy with or without hyperthermia in the treatment of superficial localized breast cancer: results from five randomized controlled trials. Int. J. Radiat. Oncol. Biol. Phys. 35, 731-744. doi: 10.1016/03603016(96)00154-X

Vistovskyy, V., Malyy, T., Pushak, A., Vas'kiv, A., Shapoval, A., Mitina, N., et al. (2014). Luminescence and scintillation properties of LuPO4-Ce nanoparticles. J. Lumin. 145, 232-236. doi: 10.1016/j.jlumin.2013.07.027

Withers, N. J., Sankar, K., Akins, B. A., Memon, T. A., Gu, T., Gu, J., et al. (2008) Rapid degradation of CdSe/ZnS colloidal quantum dots exposed to gamma irradiation. Appl. Phys. Lett. 93, 173101. doi: 10.1063/1.2978073

Wojtowicz, A. J., Balcerzyk, M., Berman, E., and Lempicki, A. (1994). Optical spectroscopy and scintillation mechanisms of CexLa1-xF3. Phys. Rev. B 49, 14880-14895. doi: 10.1103/PhysRevB.49.14880

Wojtowicz, A. J., Berman, E., Koepke, C., and Lempicki, A. (1992). Stoichiometric cerium compounds as scintillators. I. CeF3. IEEE Trans. Nucl. Sci. 39, 494-501. doi: $10.1109 / 23.159654$

Wuister, S. F., de Mello Donega, C., and Meijerink, A. (2004). Efficient energy transfer between nanocrystalline YAG:Ce and TRITC. Phys. Chem. Chem. Phys. 6, 1633-1636. doi: 10.1039/b401299b

Wust, P., Hildebrandt, B., Sreenivasa, G., Rau, B., Gellermann, J., Riess, H., et al. (2002). Hyperthermia in combined treatment of cancer. Lancet Oncol. 3, 487-497. doi: 10.1016/S1470-2045(02)00818-5

Xu, W. C., Luo, T., Li, P., Zhou, C. Q., Cui, D. X., Pang, B., et al. (2012). RGDconjugated gold nanorods induce radiosensitization in melanoma cancer cells by downregulating alpha(v)beta(3) expression. Int. J. Nanomedicine 7, 915-924. doi: $10.2147 /$ IJN.S28314

Yao, L., Daniels, J., Moshnikova, A., Kuznetsov, S., Ahmed, A., Engelman, D. M., et al. (2013). pHLIP peptide targets nanogold particles to tumors. Proc. Natl. Acad. Sci. U.S.A. 110, 465-470. doi: 10.1073/pnas.12196 65110

Zagar, T. M., Oleson, J. R., Vujaskovic, Z., Dewhirst, M. W., Craciunescu, O. I., Blackwell, K. L., et al. (2010). Hyperthermia combined with radiation therapy for superficial breast cancer and chest wall recurrence: a review of the randomised data. Int. J. Hyperthermia 26, 612-617. doi: 10.3109/02656736.2010.487194

Zhang, X.-D., Chen, J., Min, Y., Park, G. B., Shen, X., Song, S.-S., et al. (2014). Metabolizable Bi2Se3 nanoplates: biodistribution, toxicity, and uses for 
cancer radiation therapy and imaging. Adv. Funct. Mater. 24, 1718-1729. doi: 10.1002/adfm.201302312

Zhang, X. D., Guo, M. L., Wu, H. Y., Sun, Y. M., Ding, Y. Q., Feng, X., et al. (2009). Irradiation stability and cytotoxicity of gold nanoparticles for radiotherapy. Int. J. Nanomedicine 4, 165-173. doi: 10.2147/IJN.S6723

Zhang, X. D., Wu, D., Shen, X., Chen, J., Sun, Y. M., Liu, P. X., et al. (2012). Size-dependent radiosensitization of PEG-coated gold nanoparticles for cancer radiation therapy. Biomaterials 33, 6408-6419. doi: 10.1016/j.biomaterials.2012.05.047

Conflict of Interest Statement: The authors declare that the research was conducted in the absence of any commercial or financial relationships that could be construed as a potential conflict of interest.
Received: 12 August 2014; paper pending published: 24 August 2014; accepted: 21 September 2014; published online: 14 October 2014.

Citation: Cooper DR, Bekah D and Nadeau JL (2014) Gold nanoparticles and their alternatives for radiation therapy enhancement. Front. Chem. 2:86. doi: 10.3389/ fchem.2014.00086

This article was submitted to Chemical Engineering, a section of the journal Frontiers in Chemistry.

Copyright (C) 2014 Cooper, Bekah and Nadeau. This is an open-access article distributed under the terms of the Creative Commons Attribution License (CC BY). The use, distribution or reproduction in other forums is permitted, provided the original author(s) or licensor are credited and that the original publication in this journal is cited, in accordance with accepted academic practice. No use, distribution or reproduction is permitted which does not comply with these terms. 